Piia Pentti

\title{
ESITETTY VAI ELETTY NAANTALI?
}

\section{Osallisuuden ja osattomuuden dynamiikka kaupungin historiakulttuurissa}

\section{Naantali: performed or lived? Dynamics between partiality and impartiality in a city's history culture}

\begin{abstract}
This article reviews the public history culture of the municipality of Naantali in relation to the current discourses of Naantali's past. I reflect the question of authority to define what is considered historically significant and how this affects the exclusions and inclusions of identity formulation. My empirical research subject is the History of Naantali, consisting of three parts $(1959,1965,1976)$. I analyse the local history of Naantali and try to offer perspectives as to how and why this particular history is being used in the municipality's history culture. I propose that the local history selected to serve as the image for the municipality, does not generate identification among its residents. This has an effect on the municipalities' cultural politics.
\end{abstract}

Keywords: Naantali, use of history, history culture, heritage, identity work, locality

\section{Historiallinen Naantali}

Naantali on alle 20000 asukkaan lounaissuomalainen rannikkokaupunki, joka on kaupungin historiaan liitettyjen mielikuvien tähden poikkeuksellisen tunnettu sekä kansallisesti että kansainvälisesti. Naantalin kaupunkistatus ulottuu vuoteen 1443 eli paljon kauemmas menneisyyteen kuin useimpien muiden suomalaisten kaupunkien. Naantali tunnetaan birgittalaisluostaristaan, kylpylaitostoiminnastaan sekä osin keskiaikaisperäisestä vanhastakaupungistaan. Historiatietoa on hyödynnetty Naantalin imagon rakentamisessa monin tavoin.

Usein paikkakuntaan liittyvän historiatiedon halutaan herättävän kiinnostusta matkailutarkoituksissa. Aineettomia ja aineellisia menneisyyden jälkiä hyödyntävästä kulttuurimatkailusta on nopeasti muodostunut turismin suurin ja nopeimmin kasvava sektori (Timothy ym., 2009a, s. 3-7; Richards ym., 2001, s. 71-72; Poria ym., 2003, s. 239; Hovi, 2017, s. 66-67). Trendi on tunnistettu Naantalissa, jossa paikallista historiaa ja kulttuuriperintöä on pyritty aktiivisesti tuotteistamaan matkailijoiden tavoittamiseksi (Helander ym., 2005; Naantalin kaupunginvaltuusto, 2015; Naantalin Matkailu Oy, 2018). Toiminnassa on kyse historiakulttuurista, jossa osa menneisyyden jäljistä tuotetaan symboleiksi, jotka edustavat nykyisyydelle ymmärrettävää menneisyyttä (Sivula, 2015, s. 56; Lehtonen, 2000, s. 21). On tärkeää huomata, että historiatietoisuutemme rakentuu sen materiaalin varaan, mitä historiakulttuuri meille kulloinkin tarjoaa (Löfström, 2010, s. $8-13)$. Siksi on pohdittava, mistä aineksista historiakulttuuri rakentuu.

Vuosina 1959, 1965 ja 1976 julkaistu Naantalin historia on tähän päivään mennessä laajin Naantalin kaupungista tuotettu tutkimukseen perustuva historian esitys. Historian laajuudella en tarkoita yksin teoksen fyysistä, vaan myös aineetonta kokoa. Teoksen ajallinen ulottuvuus keskiajalta toisen maailmansodan jälkeisiin vuosiin kasvattaa sen varsinaista sivumääräänsä 
suuremmaksi. Naantalin julkinen historiakulttuuri rakentuu vahvasti teoksessa esitetyn menneisyyden tulkinnan varaan. Tämä tarkoittaisi, että kaupungin julkinen historiakulttuuri on pysynyt miltei muuttumattomana yli 50 vuoden ajan.

Tässä artikkelissa esittelen Naantalin historia -teosta ja siinä esitettyjä käsityksiä Naantalista ja tarkastelen, miten ne toistuvat kaupungin julkisessa historiakulttuurissa. Kysyn, millaista historiaa Naantalista on kirjoitettu, miten tätä historiaa on käytetty paikallisen identiteetin rakennusaineena ja pohdin, millaisia vaikutuksia tällä on paikallisen kulttuuripolitiikan kannalta.

\section{Historiakulttuuri ja historiatietoisuus}

Historiakulttuurin ja historiatietoisuuden käsitteitä ei ole mielekästä erottaa toisistaan, vaan ne tulisi käsittää eri näkökulmina samaan ilmiöön. Historiakulttuuri voidaan nähdä päivittäisessä kulttuurissamme näkyvänä suhteena menneisyyteen. Historiakulttuurin synnyttämä historiatietoisuus puolestaan auttaa yhteisöjä ylläpitämään ajallisen jatkumon kokemusta ja vahvistaa tunnetta yhteisön jäsenten historiallisesta yhteenkuuluvuudesta (Torsti, 2003, s. 45-47, 50). Historiatietoisuuden avulla yhteisöt muovaavat itseään koskevia kertomuksia, joihin samastuminen synnyttää yhteisön historiallisen identiteetin (Ahonen, 1998, s. 24-25; Giddens, 1994, s. 75-135). Nämä kertomukset kiinnittävät yhteisön jäsenet jaettuun historiaan ja pitävät yhteisön koossa nykyhetkessä (Davis, 2018, s. 23). Kollektiivisessa identiteetissä on kysymys yhteisesti tunnistetuista merkityksistä, joita olemme rakentaneet itsemme ja toistemme tunnistamiseksi (Kaunismaa, 1997, s. 41).

Kertomusten kriittinen tarkastelu voi auttaa meitä vapautumaan niiden asettamista rajoituksista sekä ymmärtämään, miten kertomuksia voidaan käyttää vastuullisemmin. Matkailu ja paikallinen kulttuuriperintö liittyvät erottamattomasti toisiinsa. Matkailijoille esitellään kulttuuriperinnöksi kohotettuja aineellisia ja aineettomia kulttuurimuotoja, kuten maise- mia, rakennuksia, esineitä, tapoja, käytäntöjä ja rituaaleja. Kulttuuriperinnössä on kyse menneisyyden jäljistä, jotka jokin taho on määritellyt erityisen tärkeiksi ja siten suojelemisen ja säilyttämisen arvoisiksi. Kulttuuriperintö on aina kosketuksissa omaan aikaansa, elävää ja alati uudistuvaa (Ilmonen, 2016, s. 12-13; Hovi, 2017, s. 66-67; Larsen, 2018, s. 29).

Kulttuuriperintöstatus voi lisätä paikan arvoa, synnyttää uusia työpaikkoja ja tulonlähteitä sekä turvata katoamassa olevien kulttuurimuotojen ja kohteiden säilymisen. Toisaalta kapean kulttuuriperintöpolitiikan on pelätty museoivan kulttuureja, asuinpaikkoja ja kulttuurin ilmentymiä. Pelko on herättänyt kysymyksiä siitä, miten kulttuuriperinnön arvot määritellään, kenen ääni merkitsee ja miten paikallisten huolenaiheet otetaan huomioon kulttuuriperintöä määriteltäessä ja hyödynnettäessä (Hovi, 2017, s. 66-67; Larsen, 2018, s. 29). Keskusteluissa on noussut esiin kulttuurisen vastuullisuuden käsite, joka korostaa paikallisen kulttuurin ja paikallisten asukkaiden arvojen kunnioittamista sekä kulttuuriperinnön monimuotoisuuden edistämistä (García-Rosell, 2017, s. 229-230). Paikallisten ihmisten vaikutusmahdollisuudet ja matkailun rooli yhteisöjen ja sosiaalisen kestävyyden näkökulmasta ovat nousseet 2000-luvulla tärkeiksi tutkimuskohteiksi (Höckert, 2015, s. 27; Tuulentie, 2017, s. 210-211).

Emeritusprofessori Jorma Kalela tunnistaa kaksi väylää, joita pitkin ilmiöt ja asiat tulevat historioiksi. Näistä ensimmäinen on julkinen historiakulttuuri. Tällä Kalela viittaa virallisiin historiatulkintoihin, jollaisia sisältyy esimerkiksi presidenttien ja pääministerien puheisiin, koulujen oppikirjoihin ja viranomaisten pystyttämiin muistopatsaisiin. Toisesta väylästä Kalela käyttää nimitystä kansanomainen historiakulttuuri, tarkoittaen tällä kotona ja työpaikalla kerrottua ja puhuttua, sukulaisilta ja lähiympäristöstä omaksuttuja näkemyksiä. Keskeistä molemmille historiakuvien päälähteille on asioiden ja ilmiöiden pitäminen muistamisen arvoisena tai historiaan liittyvää selitystä kaipaavina (Kalela, 2001, s. 17-19).

Kunnissa tuotettu ja ylläpidetty julkinen 
historiakulttuuri näyttäytyy muun muassa paikkakunnan ilmiasussa, suojelupäätöksissä, kulttuuritapahtumissa, perinteissä, museoiden näyttelyissä sekä tavassa, jolla paikkakuntaa esitetään. Ne välittävät asukkaille jatkuvaa ja toistuvaa kertomusta paikkakunnasta. Nämä kertomukset voivat parhaimmillaan kytkeytyä osaksi asukkaiden identiteettiä ja avata uusia paikkakunnan kokemisen mahdollisuuksia. Toisaalta imagoa palvelemaan ja matkailijoita houkuttamaan tuotetut kertomukset voivat yksinkertaistaa paikkakunnan yhteen muotiin, joka sulkee osan asukkaistaan ulkopuolelleen.

Kertomukset vaikuttavat paitsi käsityksiimme tulevaisuudesta, myös siihen, miten kiinnitymme menneisyyteen ja nykyhetkeen. Niillä on potentiaalia laajentaa tapojamme kokea, ajatella ja kuvitella tulevaa. Siksi on tärkeää, että tunnistamme tarinnankerrontaan kytkeytyvät mahdollisuudet, riskit ja rajoitukset. Kertomukset eivät vain kerro maailmasta jossa elämme, vaan myös luovat ja muokkaavat todellisuutta (Meretoja ym., 2018, s. 2-9). Historian välittämät kertomukset eivät tuota kulttuuriperintökohteita, vaan perintökohteiden tuottamiseen käytetään historiaa (Ilmonen, 2016, s. 12-13).

\section{Historiografinen operointi ja dekonstruktiivinen lukeminen}

Paikallisten menneisyyden tulkintojen kannalta tärkeässä asemassa ovat Naantalin historian kaltaiset suuret paikallishistoriat (Valkeapää, 2006, s. 80; Markkola ym., 2014, s. 7-8, s. 28-29; Sivula, 2015, s. 60-63). Paikallishistoriat nähdään usein käsikirjoina paikkakunnan menneisyyteen. Niitä hyödynnetään niin kouluopetuksessa, esitelmissä kuin viranhaltijoiden valmistelutöissä. Monet näistä paikallishistorioista on sekä tilattu että rahoitettu kuntien toimesta (Ahtiainen ym., 2010, s. 7-8, 21). Niin myös Naantalissa.

Naantalin kaupunginvaltuustossa virisi vuonna 1901 ajatus kaupungin historian tilaamisesta paikkakunnan juhlavuoden kunniaksi. Vuonna 1937 kaupunginvaltuusto nimitti historiatoimikunnan, jonka tavoitteena oli saattaa työ valmiiksi vuonna 1943 vietettävään kaupungin 500-vuotisjuhlaan mennessä. Toisen maailmansodan syttyminen hidasti historian valmistumista ja lopulta ehti kulua 75 vuotta ennen kuin kaupunkihistoria oli kokonaisuudessaan valmis. Kirjoittajien mukaan historian tilaamiseen vaikutti tarve tallentaa Naantalin maalaiskuntaan kytkeytyviä muistoja ja perinteitä (Innanmaa, 1965, s. 5; Suvanto, 1976, s. 7;

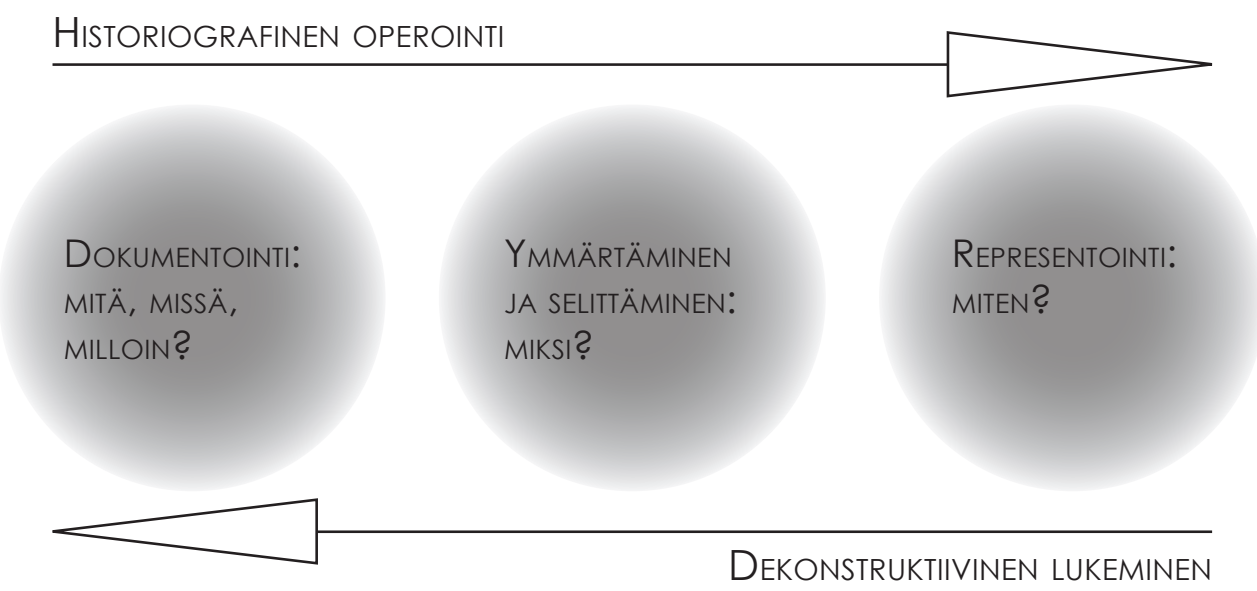

Kuva 1: Ricoeurin mukaan paikkansa pitävä menneisyyden tulkinta rakennetaan historiografisen operoinnin kolmella tasolla. Sivula kääntää mallin ylösalaisin ja lähestyy menneisyyden tulkintaa dekonstruktiivisesti. 
Jäntere \& Matinolli, 1959, s. 5). Lopputuloksena syntyi kolmiosainen Naantalin historia.

Tarkastelen Naantalin paikallishistoriaa professori Anna Sivulan kehittämää ja filosofi Paul Ricoeurin ajatukseen pohjautuvaa historiografisen operoinnin mallia noudattaen. Teoria pohjautuu Ricoeurin esittämään ajatukseen historiografisen operoinnin jakautumisesta kolmeen tasoon (Sivula, 2006, s. 38-40). Ricoeurin mukaan kaikissa tutkimukseen perustuvissa historian esityksissä on tunnistettavissa kolme tasoa, jotka erottavat tutkimuksellisen tekstin kaunokirjallisuudesta. Tasoissa on kyse tekstinominaisuuksista, joista rakentuva esitys on Ricoeurin mukaan omaksuttavissa paikkansa pitäväksi menneisyyden tulkinnaksi (Ricoeur, 2006, s. 146, 235).

Historiografisen operoinnin ensimmäinen taso on dokumentaarinen taso. Tällä tasolla operoidessaan tutkija hyödyntää jälkiluonteisia tietolähteitä pyrkiessään vastaamaan menneisyyttä koskeviin kysymyksiin. Näiden tietolähteiden tarkoitus on osoittaa, mihin kirjoittaja väittämänsä perustaa sekä vastata kysymyksiin mitä, missä ja milloin (Ricoeur 2006, s. 178). Seuraavasta tasosta Ricoeur käyttää nimeä ymmärtävä ja selittävä taso. Taso toimii siltana väitettä dokumentoivan ja menneisyyttä representoivan tason välillä. Tällä tasolla kirjoittaja esittää miksi-kysymykseen monitahoisen siksi-vastauksen (Ricoeur 2006, s. 182-185; Sivula 2006 , s. 48). Kolmas taso on representaatiotaso. Tällä tasolla kirjoittaja tuottaa juonellisen esityksen, jota tarjotaan lukijan historiatietoisuuden rakennusaineeksi. Representaatiotason tehtävä on tuottaa vastaus miten-kysymykseen sekä antaa mielekkyys sille, millaiseksi historia on aikaisemmilla operoinnin tasoilla tuotettu. Sivula kääntää tämän mallin ylösalaisin ja lähestyy sitä dekonstruktiivisesti (Sivula 2006, s. 45-46).

Sivulan mallia mukaillen aloitan analyysini representaatiotasosta, josta etenen ymmärtävän ja selittävän tason kautta historiankirjoituksen dokumentaariseen tasoon. Dekonstruktiivisessa mallissa tutkijaa ohjaa kysymys, mitä elementtejä löytyy, kun teksti puretaan kolmella tasolla. Kysyn Naantalin paikallishistorialta, millaista
Naantalia historiassa esitetään, miten kirjoittajat ymmärtävät ja selittävät historian muutoksia ja eroja sekä miten kirjoittajat perustelevat esittämänsä tosiasiaväittämät. Menetelmän tarkoitus on kyseenalaistaa se, mikä ensikatsomalta näyttää itsestäänselvältä ja pakottaa tutkija kysymään, mitä tuo itsestäänselvältä vaikuttava sana tai lause todella merkitsee. Näin teoksesta on mahdollista nostaa esiin teemoja, jotka muuten jäisivät huomaamatta.

\section{Menneisyyden tulkinnasta nykyisyyden rakennusaineeksi - paikallishistoria Naantalin historiakulttuurin lähteenä}

Etsiessäni Naantalin historiasta historiografisen operoinnin representaatiotasoa kuvaavia elementtejä minua ohjasi kysymys, millaista Naantalia historiassa esitetään. Kenen historiasta esityksessä on kyse ja miten tämä esitys on juonennettu? Etsin vastauksia näihin kysymyksiin ja kirjasin ylös tyypillisiä, teoksessa usein toistuvia teemoja. Representaatiotasolla suoritettu tarkastelu paljastaa Naantalin historian noudattavan kansallisen historiakirjoituksen kaavaa. Kyse on kaupungin kehityskertomuksesta, joka värittyy kansallisen metanarratiivin ohjaamaksi selviytymistarinaksi (ks. esim. Thijs, 2008; Saarelainen, 2012; Markkola ym., 2014; Tervonen, 2014).

Historiografisen operoinnin mallin ymmärtävällä ja selittävällä tasolla kiinnitin huomioni niihin käyttöyhteyksiin, joissa representaatiotasolla esitetyt tapahtumat saavat merkityksensä. Tällä tasolla paljastuu Naantalin historian operointi kolmella ajallisella tasolla: temaattisesti historia kattaa yli 500 vuotta kestäneen ajanjakson 1400-luvulta aina 1960-luvulle (Pentti, 2016, s. 9, 37). Näiden vuosien tapahtumat on puolestaan sijoitettu kansalliselle historiankirjoitukselle ominaisesti vuoden 1917 kontekstiin, jonka kirjoittajat ovat tuottaneet omasta ajastaan ja tutkimusperinteestään käsin (ks. esim. Tervonen, 2014, s. 158; Markkola ym., 2014, s. 17).

Pyrkiessäni tunnistamaan dokumentaarisen 
tason ominaisuuksia Naantalin historiassa kiinnitin huomioni siihen, miten kirjoittajat dokumentoivat historiassa esittämänsä tosiasiaväittämät. Kirjoittajien tällä tasolla tekemät valinnat tukevat teoksen jo lähtökohtaisesti kansallista kontekstia. Dokumentaarisella tasolla tehtyjen valintojen seurauksena tutkimus edustaa perinteistä suurmies- ja tapahtumahistoriaa sivuuttaen suurelta osin tavalliset ihmiset ja arjen elinpiirin kaupungissa (Pentti, 2016, s. 43-50). Historiografisen operoinnin dekonstruktion avulla on mahdollista ymmärtää paitsi Naantalin historian, myös kansallisen historiankirjoituksen rajoituksia.

Kolmella tasolla tarkasteltuna Naantalin historia paljastuu kaupungin selviytymistarinaksi. Historia alkaa vuodesta 1443, jolloin Naantali perustetaan birgittalaisluostarin alaisuuteen. Kertomuksen ratkaiseva konflikti koetaan 1500-luvun puolivälissä, jolloin luostaritoiminta päättyy ja kaupungin olemassaolo on uhattuna. Kielteisen kehityksen katkaisee 1700-luvulla alkanut kylpylaitostoiminta, joka täyttää luostarin jättämän tyhjiön. Toisen maailmansodan myötä kylpylaitostoiminta päättyy ja kirjoittajien huomio kiinnittyy kaupungissa 1900-luvulla alkaneeseen teollistumiseen (Pentti, 2016, s. 51). Teollistuminen ja sitä seurannut "suur-Naantalin" (Innanmaa, 1965, s. 523) synty ovat kertomuksen päätepiste, joka ratkaisee luostaritoiminnan päättymistä seuranneen konfliktin lopullisesti. Tätä tulkintaa kirjoittajat tarjoavat lukijan historiatietoisuuden rakennusaineeksi.

Sama narratiivi, teollisuutta lukuun ottamatta, toistuu kaupungin julkisessa historiakulttuurissa. Käyttökelpoisiksi historiakulttuurin rakennusaineiksi valitut luostarimenneisyys, keskiaikainen kaupunkistatus ja kylpyläturismi antavat kaupungille omintakeisen leiman, johon sisältyy nostalgiaa ja menneen maailman lumoa. Kaupungin lähihistoriaa ja kiistanalaisempaa menneisyyttä edustava teollistumisen ajanjakso on puolestaan unohtunut tai unohdettu (Pentti, 2016, s. 38-65).

Paikallisen kulttuuriperinnön suojelun, säilyttämisen ja ylläpitämisen syyt ovat usein moninaisia. Prosessin taustalla saattaa vaikuttaa halu tuottaa ja kokea nostalgiaa, pyrkimys taiteellisten arvojen turvaamiseen tai ympäristön monimuotoisuuden säilyttämiseen. Yhä useammin motiivina on alueen taloudellisen kasvun tavoittelu, sillä kulttuuriperinnön on huomattu houkuttavan matkailijoita (Timothy ym., 2009b, s. 20). Kulttuurimatkailun kasvavilla markkinoilla kulttuuriperinnöstä on tullut arvokasta ja paikallista kulttuuria on ryhdytty kaupallistamaan ja rekonstruoimaan potentiaalisia kuluttajia varten (George, 2010, s. 3, 14-15; Kaipainen, 2015, s. 65). Paikallishallinnot osallistuvat aktiivisesti paikallisen perinnön tuotteistamiseen tavoitellessaan turismin tuomaa taloudellista kasvua (Chabra ym., 2003, s. 703; George, 2010, s. 14-15). Myös Naantalissa menneisyysmielikuvia tuottamalla ja käyttämällä on pyritty paikkakunnan suotuisaan taloudelliseen kehitykseen (Naantalin kaupunginvaltuusto, 2015; Naantalin Matkailu Oy, 2018).

\section{Menneisyyden jäljestä museon myyntituotteeksi}

Erityisesti Naantalin luostarimenneisyys on teema, josta matkailijat ovat usein kiinnostuneita. Vastauksena kysyntään Naantalin museossa on pyritty kehittämään moninaisia tapoja kertoa elämästä birgittalaisluostarissa ja sen aikaisessa kaupungissa. Luostarimenneisyys on esillä museon pysyvässä näyttelyssä, jossa menneisyyttä representoidaan pienoismallien, miniatyyrihahmojen, kuvien ja tekstien avulla. Kirkon ympäristössä kuljettavalla kuuntelukävelyllä on puolestaan mahdollista kuulostella, millaisia ääniä keskiajan Naantalissa on saattanut kuulua (Pentti, 2016, s. 54-55; Naantalin kaupunki, 2017a). Keskiaikainen menneisyys on tuotteistettu museossa taitavasti myös myyntituotteeksi. Arkeologisten kaivausten yhteydessä löytyneestä muottikivestä on valmistettu kaulakoruksi muunnettu kopio museokaupassa myytäväksi. Näin museon kävijät voivat halutessaan ostaa palan kaupungin keskiaikaista menneisyyttä mukaansa (Pentti, 2016, s. 57). 


\section{Keskiaika kulttuuritapahtumien keskiössä}

Suomessa harvinainen keskiaikainen kaupunkistatus on tärkeä osa kaupungin nykyistä imagoa (Pentti, 2016, s. 55-59). Sen on huomattu tuovan kaupungille näkyvyyttä: sana keskiaika saa alueelliset ja valtakunnalliset tiedotusvälineet uutisoimaan ja ihmiset kiinnittämään uutiseen huomiota (Valkeapää, 2006, s. 89). Naantalissa esimerkiksi kaupunkiprivilegioiden myöntäminen tiettynä hetkenä koetaan niin tärkeänä, että sen muistamisesta on tehty käytäntö. Kuningas Kristoffer antoi 23. elokuuta vuonna 1443 suostumuksensa Naantalin Ailostenniemeen perustettavalle luostarille ja myönsi sen alaisuuteen perustettavalle kaupungille kauppapaikan privilegiot. Päivä on katsottu kaupungin syntymäpäiväksi ja sitä juhlitaan vuosittain moninaisin kulttuuritapahtumin.

\section{Rakennettu kulttuuriperintö kaupungin kuvastona}

Luostaritoiminnan päätyttyä Ailostenniemellä sijaitseva kirkko palveli edelleen kirkollisten toimitusten paikkana. Kirkko on yhä käytössä ja se on ainut luostarista jäljelle jäänyt rakennus. Museovirasto on tunnustanut Naantalin kirkon ja sitä ympäröivän puistomaisen alueen valtakunnallisesti merkittäväksi rakennetuksi kulttuuriympäristöksi (Museovirasto 2009a). Myös Naantalin vanhakaupunki ja sen läheisyydessä sijaitsevat kylpyläkauteen liittyvät rakennukset ovat saaneet Museoviraston tunnustuksen (Museovirasto 2009b). Kansantaloustieteilijä Jouni Kaipaisen mukaan kulttuuriperintö on keskeinen kulttuuripoliittinen väline alueellisen erityisyyden rakentamisessa. Rakennettu kulttuuriperintö on tunnistettu hyväksi erottautumisen välineeksi, joten paikalliset viranomaiset tukevat paikan merkkien ehostamista (Kaipainen, 2015, s. 66-67). Vanhankaupungin ja kirkon erityisyys on tunnistettu Naantalissa ja ne edustavat kuvastoa, jota käytetään mielellään Naantalista ulospäin viestittäessä. Kohteet edustavat Naantalin kiistatta tunnistettavimpia maamerkkejä.

\section{Menneisyys tulevaisuusvisioissa - historian käyttö kaupungin viestinnässä ja strategiassa}

Naantalin julkiseen historiakulttuuriin tutustuakseen ei ole välttämätöntä vierailla kaupungissa, sillä historiakulttuurin rakennusainekset ovat läpinäkyvästi läsnä myös kaupungin tiedotuksessa ja viestinnässä (Pentti, 2016, s. 54-61). Ulkoisen markkinoinnin ja imagonrakennuksen välineenä tärkeässä asemassa ovat erityisesti kaupungin verkkosivut (Louekari, 2009, s. 205-206). Naantalin verkkosivuilla kaupungin historian kerrotaan alkaneen 1400-luvulla, jolloin Ailostenniemeen perustettiin luostari ja sen alaisuuteen kaupunki (Naantalin kaupunki 2017b). Kertomus noudattaa Naantalin historian juonta. Luostarimenneisyyttä ja kylpylaitostoimintaa representoidaan verkkosivuilla myös kuvien avulla.

Erityisen kiinnostava on kaupungin verkkosivulta löytyvä maininta, jonka mukaan Naantali "ei ole unohtanut nunnaluostariaan". Verkkosivuilla luostarin kerrotaan olevan tärkeä osa kaupungin nykyisyyttä ja tulevaisuuden mahdollisuuksia (Naantalin kaupunki 2017b). Verkkosivuilla ei esitetä vain luostarin ja kaupungin historiaa, vaan teemat kytketään aktiiviseksi osaksi kaupungin nykyisyyttä ja tulevaisuusvisioita. Myös kaupungin tuoreimmassa strategiassa Naantalin vahvuudeksi luetaan alueen omaleimainen historia. Vaikka strategiat eivät usein sellaisenaan muutu toiminnaksi, sosiaalisiksi prosesseiksi tai rakenteiksi, on historian limittyminen osaksi strategiaa kouriintuntuva osoitus historioiden välittämien kertomusten poliittisesta ja kulttuurisesta allasta.

Myös Ulvilassa ja Raumalla keskiaikaa on käytetty tukemaan kaupungin strategiaa. Ulvilan ja Rauman historiakulttuuria tutkineen Leena Valkeanpään mukaan keskiaikaa käytetään kaupunkien nykyisyyden tukemiseen. Kuntien verkkosivuilla mainitaan keskiajasta ja ylipäätään menneisyydestä asioita, jotka sopivat kaupunkien strategioihin (Valkeapää, 2006, s. 89-90). Valkeapään mukaan ulvilalaisuudeksi yritetään tuottaa vanhan kaupungin identiteettiä puhumalla keskiaikaisesta perinteestä 
ja käyttämällä menneisyydestä tulkintaa, joka perustuu tiedolle 1300-1500-luvuille sijoittuneesta kaupunkivaiheesta (Valkeapää, 2006, s. 89-90). Niin Naantalin, Ulvilan kuin Raumankin strategiat edustavat kulttuuripolitiikan kentillä tapahtunutta muutosta kohti kulttuurin taloudellista käytettävyyttä korostavia diskursseja (ks. esim. Ilmonen, 2009, s. 44-45). Naantali ja sen julkinen historiakulttuuri ovat tyypillisiä esimerkkejä Suomen keskiaikaisten kaupunkien joukossa.

\section{Kenen Aurinkokaupunki? - Naantali kotiseutuna ja matkakohteena}

Erilaisten kulttuurilaitosten ja kulttuuripalveluiden on katsottu vahvistavan ja parantavan paitsi kaupungin imagoa, myös sen identiteettiä (Kainulainen, 2005, s. 47). Kotiseutumuseot, kotiseutupäivät ja muu kotiseudun ympärille rakennettu paikallisuustoiminta luo tietoisesti tai tiedostamatta kuvaa jonkinlaisesta kuvitellusta yhteisöstä, jonka kautta toisilleen tuntemattomat ihmiset voivat asettaa itsensä historialliseen jatkumoon (Mäkinen, 2007, s. 21). Historiaansa käyttämällä kunnat pyrkivät kiinnittämään asukkaansa yhteisen kulttuuriperinnön tukemaan identiteettiin (Siivonen, 2009, 68; Mäkinen, 2007, s. 29). Parhaimmassa tapauksessa historiakulttuurin tuotteet toimivat kollektiivisesti jaettuina kertomuksina ja paikkakuntalaisten yhteenkuuluvuutta tuottavana ja ylläpitämänä resurssina (Sivula, 2015, s. 64; Mäkinen, 2007, s. 20, 120; Hieta ym., 2015, s. 316).

Kulttuuripolitiikan kannalta ongelmallista on se, että kunnat ovat samanaikaisesti sitoutuneet markkinamenestyksen tavoitteluun ja paikallisen identiteetin tukemiseen ja tuottamiseen. Kunnista pyritään luomaan toisaalta yhteisöllisyyden ja kotoisuuden, toisaalta menestyksen ja dynamiikan mielikuvia. Simo Häyrysen mukaan todellisuus ei ole tällöin enää tärkeää, vaan saattaa osoittautua jopa haitalliseksi markkinaorientoituneen tulosajattelun näkökulmasta (Häyrynen, 2006, s. 213). On vaara, että paikkakuntalaisten henkilökohtaiset kokemukset irtoavat keinotekoisesti luodusta paikallisuusmielikuvasta ja paikallisuus jää julkisen representaation tasolle (Mäkinen, 2007, s. 114; Ilmonen, 2009, s. 55; Ilmonen, 2016, s. 21). Vaikka kaikki identiteetit ovat jossain määrin manipuloituja, on niiden oltava kosketuksissa myös reaalimaailmaan, mikäli ihmisten halutaan todella kiinnittyvän niihin (Paasi, 2003, s. 478; Häyrynen, 2006, s. 196). Myyvä perinne voi myös edellyttää muiden, kilpailevien mutta yhtä oikeutettujen identiteettitulkintojen sivuuttamista (Häyrynen, 2006, s. 213).

Ihmiset pyrkivät hahmottamaan itseänsä ja elämäänsä käytettävissä olevien kertomusten avulla. Näiden kertomusten luonteeseen kuuluu, että ne uudistuvat, elävät ja muuttuvat jatkuvasti. Ne eivät sijaitse tyhjiössä, vaan muovautuvat yhä uudelleen ja uudelleen henkilökohtaisten ja yhteisöllisten kokemusten mukana (Webster ym., 2007, s. 2-3). Perinteisesti kertomuksilla on ajateltu olevan alku, keskikohta ja loppu; kun kertomus on päättynyt, paljastuu, mistä lopulta oli kyse (Cavarero, 2000, s. 123).

Naantalin historiakulttuurin rakennusaineeksi on omaksuttu historia, joka on ajateltu muuttumattomaksi, jo päättyneiden tapahtumien sarjaksi. Naantalissa kaupungin julkinen historiakulttuuri on pysynyt miltei muuttumattomana yli 50 vuoden ajan (Pentti, 2016, s. 66-76). Ongelmaksi muodostuu, ettei Naantalin julkinen historiakulttuuri reagoi omaan aikaansa. Se ei jätä tilaa kulttuuriperintöprosesseille ja identiteettien uudelleenmäärittelylle. Todellisuudessa kertomus paikkakunnasta elää, muuttuu ja on alati liikkeessä. Loppuja ei ole. Vuosikymmeniä muuttumattomina pysyneet historiakäsitykset ovat johtaneet kaupungin sisäisiin autostereotypioihin (Pentti, 2016, s. 68). Stereotypiat esittävät kohteen erityispiirteet luonnollisina ja pysyvinä sekä määrittelevät yhteisölle rajat, jotka ovat kiinteitä, selvärajaisia ja joustamattomia. Toiminta kytkeytyy usein valtarakenteisiin ja on osa sosiaalisen ja symbolisen järjestyksen ylläpitoa. Sitä, mikä on "poissa paikoiltaan", pidetään helposti uhkaavana tai vaarallisena (Sassi, 2002, s. 64). Julkisen historiakulttuurin määrittelemä naantalilaisuus rakentuu ulossulkevalle ajatukselle yhdestä ja 


\section{$\bigcirc$}

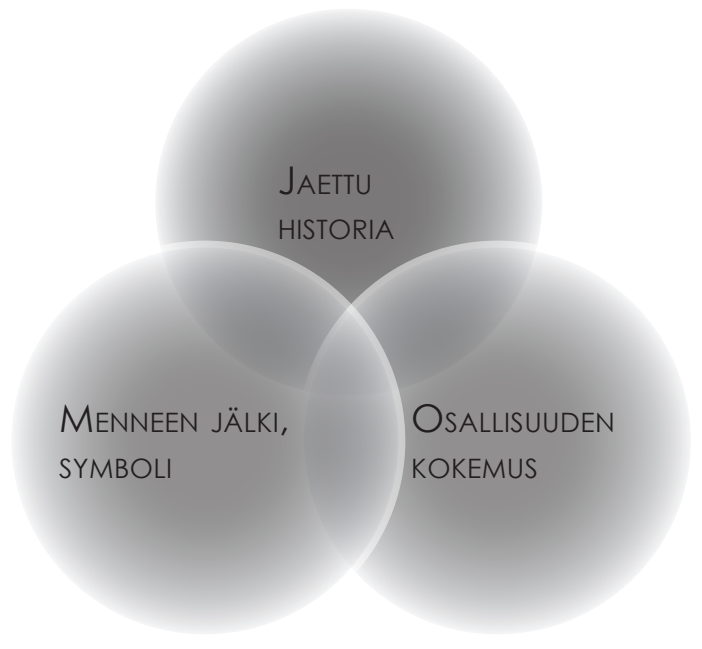

Kuva 2: Kulttuuriperintö rakentuu osallisuuskokemuksista, jaetusta historiasta ja omaksi koetun menneisyyden aineellisista tai aineettomista jäljistä. Kolmen ympyrän leikkausalveella on käynnissä kulttuuriperintöprosessi.

oikeasta kulttuurista.

Osallisuus on noussut keskeiseksi teemaksi 2010-luvun kulttuuripoliittisissa keskusteluissa. Valtaistumisen käsitteeseen linkittyvä osallisuus pitää sisällään sekä tunnetta että toimintaa: tunnetta kuulumisesta sekä vaikuttamiseen osallistumista. Kuulumisen tunteeseen ja mahdollisuuteen osallistua vaikuttavat paitsi yksilön voimavarat myös yhteiskunnan tarjoamat resurssit ja asenneilmapiiri. Osallisuuden vastakohtana on puhuttu usein syrjäytymisestä. Terminä syrjäytymisen on katsottu viittaavan yksilön omaan toimintaan, vaikka laajemmat yhteiskunnalliset eriarvoisuuden rakenteet huomioon ottaen tulisi puhua syrjäytetyksi tulemisesta. Osallisuuden kokemuksellisuutta ajatellen harva kokee itsensä syrjäytyneeksi vaan pikemminkin syrjään jätetyksi (Sassi, 2002, s. 59; Honkasalo ym., 2015, s. 25; Virolainen, 2015, s. 102).

Ihmisille on tärkeä kokea kuuluvansa johonkin paikkaan, ja he kiinnittyvät paikkaan historioiden kautta. Kunnallisessa kontekstissa tämä tarkoittaa eräänlaista hallinnan tunnetta ja kokemusta symbolisesta omistajuudesta kotikuntaa kohtaan (Mäkinen, 2007, s. 21, 27, 108-111). Vaikka paikallisuus ja paikalliskult- tuurit yhdistetään yhä useammin matkailuun, on arjen tuotteistamisen on tapahduttava paikallisten asukkaiden ehdoilla (Hakkarainen ym., 2017, s. 9-13). Tämä edellyttää, että kunnat ovat tietoisia siitä, millaista historiaa ne käyttävät identiteettiensä rakennusaineena. Paikallishistoriallisena teoksena Naantalin historia tarjoaa yhden mahdollisen tavan jäsentää todellisuutta ja rakentaa paikallista identiteettiä. Tämä ei kuitenkaan tarkoita, että se olisi ainoa ja oikea kyseisessä kulttuurissa saatavilla oleva tapa hahmottaa todellisuutta.

Kertomuksilla on valtaa laajentaa tai köyhdyttää mahdollisen tajuamme. Mahdollisuuden tajuinen yksilö kykenee tunnistamaan todellisuudessa piileviä mahdollisuuksia ja ajattelemaan, miten asiat voisivat olla toisin. Omaksumamme menneisyyden tulkinnat vaikuttavat siihen, mitä näemme mahdollisena nykyhetkessä (Meretoja, 2018, s. 299-301). Siksi ei ole yhdentekevää, millaisia historioita kunnat käyttävät identiteettiensä rakennusaineena.

Ricoeur korostaa, että jokainen kertomus on mahdollista kertoa toisin. Samoista menneisyyden tapahtumista voidaan esittää lukuisia toisistaan poikkeavia tulkintoja. On tärkeää, että yksilöt ja yhteisöt saavat määritellä oman his- 
toriansa, sillä näiden kertomusten varaan rakentuu yhteisön kollektiivinen muisti (Ricoeur, 1999, s. 7-9). Naantalissa olisi hyödyllistä pohtia nykyhetkestä käsin, keitä me olemme ja millaisen historian tulosta tämä on.

\section{Yhteisöllinen historia haastaa vakiintuneita historiatulkintoja}

Naantalin tilannetta voidaan ryhtyä ratkaisemaan soveltamalla siihen Anna Sivulan erittelemiä identiteettityökaluja. Sivula on tunnistanut kolme identiteettityökalua, joilla kulttuuriperintöprosessia ylläpitävät yhteisöt operoivat. Näitä ovat jaettu historia, osallisuuskokemus sekä jaetun historian todisteina toimivat menneisyyden jäljet ja symbolit.

Jaettu historia tarkoittaa sitä menneisyyden tulkintaa, jonka yhteisön jäsenet jakavat keskenään ja jota he esittelevät ulospäin omana historianaan. Jaettua historiaansa käyttämällä yhteisö määrittelee, mitkä menneisyyden jäljet ovat säilyttämisen ja suojelun arvoisia ja mitä puolestaan voidaan unohtaa tai himmentää pois. Jaettu historia on Sivulan sanoin sekä inklusiivista että eksklusiivista: historia kiinnittää aiempaa vahvemmin yhteisön jäseniksi ne, jotka kokevat osallisuutta historialla merkitystä menneisyydestä ja korostaa niiden ulkopuolisuutta, jotka eivät ole osallisia. Osallisuuskokemuksella Sivula tarkoittaa kulttuuriperintöyhteisön jäsenten kokemaa osallisuutta paitsi jaetusta historiasta, myös tämän historian esittämän menneisyyden symboleista ja jäljistä. Nämä menneisyyden jäljet ja symbolit toimivat jaetun historian todisteina (Sivula, 2015, s. 64-65).

Kunnat näyttäisivät jossain määrin operoivan Sivulan mallin kaltaisilla identiteettityökaluilla tuottaessaan paikallista historiakulttuuria ja kulttuuripolitiikkaa, mutta operointi ei ole reflektoivaa. Jaettu historia on rinnastettavissa kunnan itsestään omaksumaan ja hyväksymään menneisyyden tulkintaan. Usein tähän rooliin asettuvat paikallishistoriat, joista valtaosa on sekä rahoitettu että tilattu kuntien toimesta. Paikallishistorioihin tukeutuen kunnat nostavat esiin menneisyydestä merkittäviksi katsomiaan symboleja. Ongelmallista on, jos historia joka yhteisön on tarkoitus jakaa, on tuotettu ilman kuntalaisten riittävää osallistamista. Auktoriteettiasemasta määritelty kunnallishistoria ei riitä synnyttämään osallisuuskokemusta.

Menneisyyden symbolit, joiden taustalta puuttuu osallisuuskokemus, eivät riitä identiteetin rakennusaineiksi. Identiteettien perustana eivät ole ylhäältä annetut abstraktit sloganit, vaan ne rakentuvat sosiaalisille ja kulttuurisille käytännöille, diskursseille ja toiminnalle (Paasi, 2003, s. 478; Mäkinen, 2007, s. 20-21, 120). Osallisuuden kokeminen niin jaetusta historiasta kuin tämän historian esittämän menneisyyden symboleista ja jäljistä on mahdollista vain, jos ihmiset saavat olla itse mukana määrittämässä oman kotiseutunsa kulttuuria ja siten kulttuuripolitiikkaa. Vastavuoroisesti kulttuuripolitiikasta vastaavien viranhaltijoiden ja päätöksentekijöiden on ymmärrettävä, millaisessa yhteisössä he operoivat ja missä määrin sen jäsenet ovat edustettuina.

Mikäli historioiden halutaan tarjoavan kuntalaisille työkaluja identiteettien ja yhteisöllisyyden rakentamiseen on tulevaisuudessa tärkeää, että paikallisyhteisöt kiinnitetään alusta alkaen historioiden tuottamiseen. Vain näin historia on mahdollista rakentaa palvelemaan sitä yhteisöä, jonka menneisyydestä se kertoo. Historian kirjoittajien on opeteltava tuntemaan kunnan viranhaltijoita ja päätöksentekijöitä laajempi kulttuuriperintöyhteisö ja kysyttävä, mikä heidän menneisyydessään on tärkeää. Paikallinen kulttuuriperintö katoaa nopeasti, elleivät paikalliset ihmiset kytke sitä osaksi omaa identiteettiään. Yhteisöllisen historian avulla voidaan paitsi tukea paikallisten asukkaiden identiteettityötä, myös rakentaa merkitys sellaisille menneisyyden jäljille, jotka ilman historiallista kontekstia jäisivät käsittämättömiksi ja selittämättömiksi. Kun menneisyyden jäljille rakennetaan historiallinen merkitys, niistä tulee kulttuuriperintöä (Sivula, 2017, s. 8-10).

Suomessa paikallishistoriat ovat perinteisesti noudattaneet kansallisen historiankirjoituksen kaavaa, jossa nationalistinen näkökulma on ohjannut niin aiheiden kuin aineistojen tulkintaan. Paikallishistorialle tämä konteksti 
on marginaalinen ja kertoo enemmän omasta ajastaan kuin historioitavasta menneisyydestä. Tästä huolimatta Naantalin historian kaltaiset suuret kaupunkihistoriat ovat saaneet keskeisen roolin paikallisissa menneisyyden tulkinnoissa. On todennäköistä, että Naantalin tavoin monissa Suomen kunnissa ja kaupungeissa julkisen historiakulttuurin kertomusytimen muodostavat kansallisen historiankirjoituksen kaavaa noudattavat paikallishistoriat. Vaikka artikkelin empiirisen kuvauksen voidaan olettaa olevan jossain määrin yleistettävissä, ei tuloksia voida sellaisenaan siirtää muiden kuntien ja kaupunkien kontekstiin. Artikkelissa olen pyrkinyt lisäämään rajallista ymmärrystä ilmiöstä, josta tarvitaan kipeästi lisää tutkimusta. Tavoitteeni on edistää paikallishistorioiden yhteisöllisyyttä ja normalisoida yhteisöllisen paikallishistorian menetelmiä.

Tutkimustieto voi avata keskustelua siitä, miten kulttuuriperintöä määritellään, hyödynnetään ja ylläpidetään sen henkisesti jakavan kulttuuriperintöyhteisön kanssa. Kulttuuripolitiikan näkökulmasta keskeistä on paitsi pyrkimys kulttuuriperintöprosessien demokratisointiin, myös kulttuuriperintöön liittyvän ymmärryksen ja sensitiivisyyden lisääminen poliittishallinnollisissa instituutioissa (Larsen, 2018, s. 31). Samalla tarvitaan lisäymmärrystä siihen, miten uudenlaiset kulttuuriin osallistumisen muodot muuttavat kulttuurikäyttäytymistä ja -käsitystä, sekä siihen, mitä tämä tarkoittaa kulttuuripolitiikan kannalta (Virolainen, 2015, s. 104; Sassi, 2002, s. 58). Varmaa kuitenkin on, että tulevaisuudessa kunnilta ja kaupungeilta tarvitaan halua ja kykyä luovuttaa päätösvaltaa paikallisille kulttuuriperintöyhteisöille kotiseutujen tuottamisessa.

\section{Lähteet ja kirjallisuus}

\section{Tutkimusaineisto}

Innanmaa, K. (1965). Naantalin historia 3. Suomen sodasta itsenäisyyden aikaan. Naantalin kaupunki: Turku.

Jäntere, K. \& Matinolli, E. (1959). Naantalin historia 2. Kaupunki ja seurakunta luostariajan lopusta Suomen sotaan. Naantalin kaupunki: Turku.

Suvanto, S. (1976). Naantalin historia 1. Keskiaika ja 1500-luku. Turku: Naantalin kaupunki.

\section{Tutkimuskirjallisuus}

Ahonen, S. (1998). Historiaton sukupolvi? Historian vastaanotto ja historiallisen identiteetin rakentuminen 1990-luvun nuorison keskuudessa. Suomen historiallinen seura: Helsinki.

Ahtiainen, P. \& Tervonen, J. (2010). Paikallishistorian pitkä kaari - ja tulevan akateemikon kri- ittinen katse. P. Ahtiainen \& J. Tervonen (toim.). Kaikella on paikkansa. Uuden paikallishistorian suuntaviivoja. (27-90). Vastapaino: Tampere.

Cavarero, A. (2000). Relating Narratives. Storytelling and selfhood. Routledge: Abingdon.

Chhabra, D., Healy, R. \& Sills, E. (2003). Staged Authenticity and Heritage Tourism. Annals of Tourism Research, 30 (3), 702-719. DOI: 10.1016/S0160-7383(03)00044-6

Davis, C. (2018). Truth, Ethichs, Fiction. Responding to Plato's Challenge. H. Meretoja \& C. Davis (toim.). Storytelling and Ethics. Literature, Visual Arts and the Power of Narrative. (2336). Routledge: Abingdon.

Garcia-Rosell, J. (2017). Vastuullinen matkailu. J. Edelheim \& H. Ilola (toim.). Matkailututkimuksen avainkäsitteet. (229-234). Lapland University Press: Rovaniemi. 
George, W. (2010). Intangible cultural heritage, ownership, copyrights, and tourism. International Journal of Culture Tourism and Hospitality Research, 4 (4), 376-388. DOI: $10.1108 / 17506181011081541$

Giddens, A. (1994). Life in Post-Traditional society. Reflexive Modernization. Politics, Tradition and Aesthetics in the Modern Social Order. Polity Press: London.

Hakkarainen, M. \& Haanpää, $M$. \& Ilola, $H$. (2017). Johdanto. M. Hakkarainen \& $M$. Haanpää \& H. Ilola (toim.) Paikallinen arki matkailussa. (8-13). Matkailualan tutkimus- ja koulutusinstituutti: Rovaniemi.

Honkasalo, M. \& Laukkanen, A. (2015). Osallisuus ja yhteisöllisyys hyvinvointia edistämässä. Taiteen ja kulttuurin vaikuttavuuden arviointi EU-hankkeissa. Kulttuuripolitiikan tutkimuksen vuosikirja 2015. Kulttuuripolitiikan tutkimuksen seura ry. DOl: https://doi.org/10.17409/ kpt.vli1.100

Hovi, T. (2017). Kulttuurimatkailu. J. Edelheim \& H. Ilola (toim.) Matkailututkimuksen avainkäsitteet. (64-69). Lapland University Press: Rovaniemi.

Häyrynen, S. (2006). Suomalaisen yhteiskunnan kulttuuripolitiikka. Jyväskylän yliopisto: Jyväskylä.

Höckert, E. (2015). Ethics of hospitality. Participatory Tourism Encounters in the Northern Highlands of Nicaragua. Lapin yliopisto: Rovaniemi.

Ilmonen, K. (2009). Kulttuuri ja aluekehittäminen. Konflikteja ja kommunikaatiota. M. Grahn \& M. Häyrynen (toim.) Kulttuurituotanto. Kehykset, käytäntö ja prosessit. (44-61). Suomalaisen Kirjallisuuden Seura: Helsinki.

Ilmonen, K. (2016). Kulttuuriperintö maaseudun matkailuyritysten tuotteissa ja palveluissa. Jyväskylän yliopisto: Kokkola.

Kaipainen, J. (2015). Maaseudun kulttuuriperinnön hyödyntäminen. Maaseudun uusi aika, 3/2015, 65-74. URL: www.mua-lehti.fi/ maaseudun-kulttuuriperinnon-hyodyntaminen/

Kainulainen, K. (2005). Kunta ja kulttuurin talous. Tulkintoja kulttuuripääoman ja festivaalien aluetaloudellisista merkityksistä. Tampereen yliopisto. URL: http://urn.fi/urn:isbn:951-446439-7

Kalela, J. (2001). Historiantutkimus ja jokapäiväinen historia. J. Kalela \& I. Lindroos (toim.) Jokapäiväinen historia. (1 1-25). Suomalaisen Kirjallisuuden Seura: Helsinki.

Kaunismaa, P. (1997). Mikä on kollektiivinen identiteetti. K. Virtapohia (toim.) Puheenvuoroja identiteetistä. Johdatusta yhteisöllisyyden ym- märtämiseen. Atena Kustannus Oy: Jyväskylä. Larsen, P. (2018). Democratic heritage and heritage-based democracies. URL: www.researchgate.net/publication/32501 2777

Lehtonen, M. (2000). Merkitysten maailma. Vastapaino: Tampere.

Louekari, S. (2009). Satakunta esitettynä maisemana. M. Grahn \& M. Häyrynen (toim.) Kulttuurituotanto. Kehykset, käytäntö ja prosessit. (194-214). Suomalaisen Kirjallisuuden Seura: Helsinki.

Löfström, J. (2010). Historian valokeilassa. Museo, 3/2010, 8-13. Suomen Museoliitto: Helsinki.

Malmivirta, H. \& Taivainen, A. (2012). Muutoksen mahdollisuus. H. Malmivirta \& A. Taivainen (toim.) Merkittävien ihmisten yhteiskunta. Hymykuopat-hanke kunnan tarpeisiin vastaajana. (8-1 1). Salon kaupunki, kulttuuripalvelut: Salo.

Markkola, P. \& Snellman, H. \& Östman, A. (2014). Kotiseutu ja kansakunta. Miten suomalaista historiaa on rakennettu. Suomalaisen Kirjallisuuden Seura: Helsinki.

Meretoja, H. (2018). The Ethics of Storytelling. Narrative Hermeneutics, History, and the Possible. Oxford University Press: New York.

Meretoja, H. \& Davis, C. (2018). Introduction. H. Meretoja \& C. Davis (toim.) Storytelling and Ethics. Literature, Visual Arts and the Power of Narrative. (6-26). Routledge: Abingdon.

Museovirasto. (2009a). Naantalin kirkko ja Ailostenniemi. (Haettu 1.4.2018.) URL: www.rky. $\mathrm{fi} / \mathrm{read} / \mathrm{asp} / \mathrm{r}$ _kohde_det.aspx?KOHDE_ ID $=1789$

Museovirasto. (2009b). Naantalin vanhakaupunki. (Haettu 1.4.2018.) URL: www.rky.fi/read/asp/r_kohde_det.aspx?KOHDE_ID $=1787$

Mäkinen, M. (2007). Kotikunta kaupunginosaksi. Säynätsalon kunnan ja Jyväskylän kaupungin kuntaliitos kulttuurisena ilmiönä. Jyväskylän yliopisto. URL: http://urn.fi/URN:NBN:fi:iyu-2007489

Naantalin kaupunginvaltuusto. (2015). Naantalin kaupunkistrategia 2020. Kaikkien Kultaranta. URL: issuu.com/naantalin_kaupunki/docs/ naantalin_kaupunki_210×210_1-12_iss

Naantalin kaupunki. (2017a). Kaikuja keskiajalta -kuuntelukävely. (Haettu 1.4.2018.) URL: www.naantali.fi/kulttuuri/nlin_museo/fi_Fl/ kaikuja_keskiajalta/

Naantalin kaupunki. (2017b). Historia. (Haettu 1.4.2018.) URL: www.naantali.fi/Kunta-info/ historiaa/fi_Fl/naantalin_historia/

Naantalin Matkailu Oy. (2018). Omaperäinen Naantali year-round/365. Naantalin MatkaiIun masterplan. URL: http://aleksis.naantali.fi/ 
poytakirjat/kokous/20182892-4-1.PDF

Paasi, A. (2003). Region and place: regional identity in question. Progress in Human Geography, 27 (4), 475-485. URL: https://doi. org/10.1191/0309132503ph439pr

Pentti, P. (2016). Menneisyyden tulkinnasta nykyisyyden rakennusaineeksi: Naantalin kaupungin historiakulttuurin tarkastelua yhden paikallishistorian kautta. Turun yliopisto. URL: http://urn. fi/URN:NBN:fi-fe2016102525588

Poria, Y. \& Butler, R. \& Airey, D. (2003). The Core of Heritage Tourism. Annals of Tourism Research, 30 (1), 238-254. URL: http://epubs. surrey.ac.uk/id/eprint/1 103

Richards, G. \& Goedhart, S. \& Herrijgers, C. (2001). The Cultural Attraction Distribution System. G. Richards (toim.) Cultural Attractions and European Tourism. (71-89). CABi: Wallingford.

Ricoeur, P. (1999). Memory and Forgetting. R. Kearney \& M. Dooley (toim.). Questioning Ethics. Contemporary Debates in Philosophy. Routledge: Padstow.

Ricoeur, P. (2006). Memory, history, forgetting. Chicago \& London: The University of Chicago Press.

Saarelainen, J. (2012). Konteksti ja kontekstualisoiminen. A. Nivala \& R. Mähkä (toim.) Tulkinnan polkuja. Kulttuurihistorian tutkimusmenetelmiä. 244-268. Turun yliopisto: Turku.

Sassi, S. (2002). Kulttuurinen identiteetti ja osallisuus. Bäcklund, P., Häkli, J. \& Schulman, H. (toim.). Osalliset ja osaajat. Kansalaiset kavpungin suunnittelussa. 58-74. Gaudeamus: Helsinki.

Siivonen, K. (2009) Osallistava kulttuurituotanto. Pohdintaa kulttuurisesta kestävyydestä. Grahn, M. \& Häyrynen, M. (toim.). Kulttuurituotanto. Kehykset käytäntö ja prosessit. 137-162. Suomalaisen Kirjallisuuden Seura: Helsinki.

Sivula, A. (2006). Kysymyksiä ja voimaviivoja. March Blochin historiantutkimuksellisen tuotannon metodologinen perintö. Väitöskirja. Turun yliopisto: Turku.

Sivula, A. (2015). Tilaushistoria identiteettityönä ja kulttuuriperintöprosessina: Paikallisen historiapolitiikan tarkastelua. Kulttuuripolitiikan tutkimuksen vuosikirja 2015, 56-69.

Sivula, A. (2017). Monipaikkainen Merikarvian kulttuuriperintöyhteisö, monen kirjoittajan teos, moniääninen historia. A. Sivula \& R. Haanpää \& A. Ruohomäki (toim.) Kuunarin kryssi. Merikarvialaisten historiaa 1860-luvulta 2000-luvulle. 8-12. Merikarvian kunta: Merikarvia.
Tervonen, M. (2014). Historiankirioitus ja myytti yhden kulttuurin Suomesta. P. Markkola \& H. Snellman \& A. Östman (toim.) Kotiseutu ja kansakunta. Miten suomalaista historiaa on rakennettu. (137-162). Suomalaisen Kirjallisuuden Seura: Helsinki.

Thiis, K. (2008). The Metaphor of the Master: 'Narrative Hierarchy' in National Historical Cultures of Europe. S. Berger \& C. Lorenz (toim.) Contested nation. Ethnicity, class, religion and gender in national histories. (60-74). European Science Foundation: Basingstoke.

Timothy, D. \& Nyaupane, G. (2009a). Introduction: Heritage tourism and the less-developed world. D. Timothy \& G. Nyaupane (toim.) 2009: Cultural Heritage and Tourism in the Developing World. A Regional Perspective. (3-19). Routledge: New York.

Timothy, D. \& Nyaupane, G. (2009b). Protecting the past. Challenges and opportunities. D. Timothy \& G. Nyaupane (toim.) 2009: Cultural Heritage and Tourism in the Developing World. A Regional Perspective. (20-41). Routledge: New York.

Torsti, P. (2003). Divergent Stories, Convergent Attitudes. A study on the presence of history, history textbooks and the thinking of youth in post-war Bosnia and Herzegovina. Kustannus Oy Taifuuni: Helsinki.

Tuulentie, S. (2017). Matkailun sosiologia. J. Edelheim \& H. llola (toim.) Matkailututkimuksen avainkäsitteet. (207-211). Lapland University Press: Rovaniemi.

Valkeapää, L. (2006). Käyttökelpoinen keskiaika. Historiakulttuuria nykypäivän Ulvilassa ja Raumalla. Alue ja Ympäristö, 35 (2), 79-91. URL: https://aluejaymparisto.journal.fi/article/view/64300

Virolainen, J. (2015). Näkökulmia osallistumiseen, osallisuuteen ja osallistumattomuuteen taiteen ja kulttuurin kentällä. Kulttuuripolitiikan tutkimuksen vuosikirja 2015, 100-107. Kulttuuripolitiikan tutkimuksen seura ry. DOI: https:// doi.org/10.17409/kpt.vli1.103.

Webster, L. \& Mertova, P. (2007). Using Narrative Inquiry as a Research Method. An introduction to using critical event narrative analysis is research on learning and teaching. Routledge: Padstow. 